\title{
๖The Shelf Sources of Estuarine Inflow
}

\author{
ElizABETH BRASSEALE ${ }^{\mathrm{a}}$ AND PARKER MACCREADY ${ }^{\mathrm{b}}$ \\ ${ }^{\text {a }}$ Scripps Institution of Oceanography, La Jolla, California \\ ${ }^{\mathrm{b}}$ School of Oceanography, University of Washington, Seattle, Washington
}

(Manuscript received 15 April 2020, in final form 29 April 2021)

\begin{abstract}
The inflow to an estuary originates on the shelf. It flushes the estuary and can bring in nutrients, heat, salt, and hypoxic water, having consequences for estuarine ecosystems and fjordic glacial melt. However, the source of estuarine inflow has only been explored in simple models that do not resolve interactions between inflow and outflow outside of the estuarine channel. This study addressed the estuary inflow problem using variations on a three-dimensional primitive equation model of an idealized estuarine channel next to a sloping, unstratified shelf with mixing provided by a singlefrequency, 12-h tide. Inflow was identified using particle tracking, momentum budgets, and total exchange flow. Inflow sources were found in shelf water downstream of the estuary, river plume water, and shelf water upstream of the estuary. Downstream is defined here with respect to the direction of coastal trapped wave propagation, which is to the right for an observer looking seaward from the estuary mouth in the Northern Hemisphere. Downstream of the estuary and offshore of the plume, the dynamics were quasigeostrophic, consistent with previous simple models. The effect of this inflowing current on the geometry of the river plume front was found to be small. Novel sources of inflow were identified which originated from within the plume and upstream of the estuary.
\end{abstract}

KEYWORDS: Continental shelf/slope; Estuaries; Density currents; Ocean models; Regional models; Tracers

\section{Introduction}

The mixed water within an estuary is composed of river water and a significant amount of ocean water that originates on the shelf. Much has been written about the path by which mixed water leaves the estuary as a river plume (HornerDevine et al. 2015). Here we focus on the path by which dense ocean water is drawn into the estuary from the shelf, hereafter "shelf inflow."

Shelf inflow is a persistent estuarine feature, robust under a variety of forcing conditions. Scaling analysis of estuaries dominated by gravitational circulation has shown that the rate of estuarine exchange flow varies only with bathymetry and river flow, and the variation due to river flow is weak (Ralston et al. 2008; MacCready and Geyer 2010). Shelf inflow was found to be an important controller of residence time in a box model of the Strait of Georgia while variability in Fraser River runoff had little impact on residence time (Pawlowicz et al. 2006). Banas et al. (2004) also found a low correlation between river flow and salt transport in Willapa Bay off the Oregon coast, showing that a hundred-fold increase in river flow only increased salt transport by a factor of three. Meanwhile, shelf inflow propagated into the bay even during low-flow and noflow conditions because of lateral tidal stirring. Numerical simulations of Chesapeake Bay found shelf inflow to originate from the left of the estuary, facing seaward from the mouth, but this may have resulted from the mean southward coastal current (Valle-Levinson et al. 1996). Theoretical models have

¿ Denotes content that is immediately available upon publication as open access.

Corresponding author: Elizabeth Brasseale, ebrasseale@ucsd.edu suggested that, in the absence of shelf currents, shelf inflow would originate from the right of the estuary, facing seaward, in the Northern Hemisphere (Beardsley and Hart 1978; Masse 1990).

Inflowing shelf water can have a large impact on the biogeochemical characteristics of estuaries. Shelf water that is drawn into the estuary flushes the resident estuarine water. Inflow to the Salish Sea, for example, is episodically found to originate in the deep abyssal Pacific and have high nitrate but low oxygen, aragonite saturation, and $\mathrm{pH}$. One path into the Salish Sea via the Strait of Juan de Fuca has been observed in the Juan de Fuca canyon during upwelling-favorable winds, which enables water from below the shelf break to reach the Salish Sea (Alford and MacCready 2014). This hypoxic deep-water signature has been observed throughout the Salish Sea and in Puget Sound (Feely et al. 2010). A comprehensive numerical model of the Pacific Northwest coastal waters has shown the importance of exchange flow on nutrient availability on the shelf. Ninety-eight percent of the available nutrients in the outflow of the Strait of Juan de Fuca originated in the ocean, brought into the fjord-like estuary as inflow and upwelled to the surface through mixing processes (Davis et al. 2014). There has also been evidence that exchange flow in estuaries plays a major role in the transport of nutrients on continental shelves. A three-dimensional model study of the Columbia River plume noted the influence of estuarine exchange flow on cross-shelf exchange: $25 \%$ more water was exchanged across the shelf when flow from the Columbia River was included in the model (Banas et al. 2009).

In glacial fjords, the thermal content of inflow can change the melting rate of glaciers (Sutherland and Straneo 2012). Fjord temperature is increasingly recognized to be important for glacier melt, as recent observations near a tidewater 

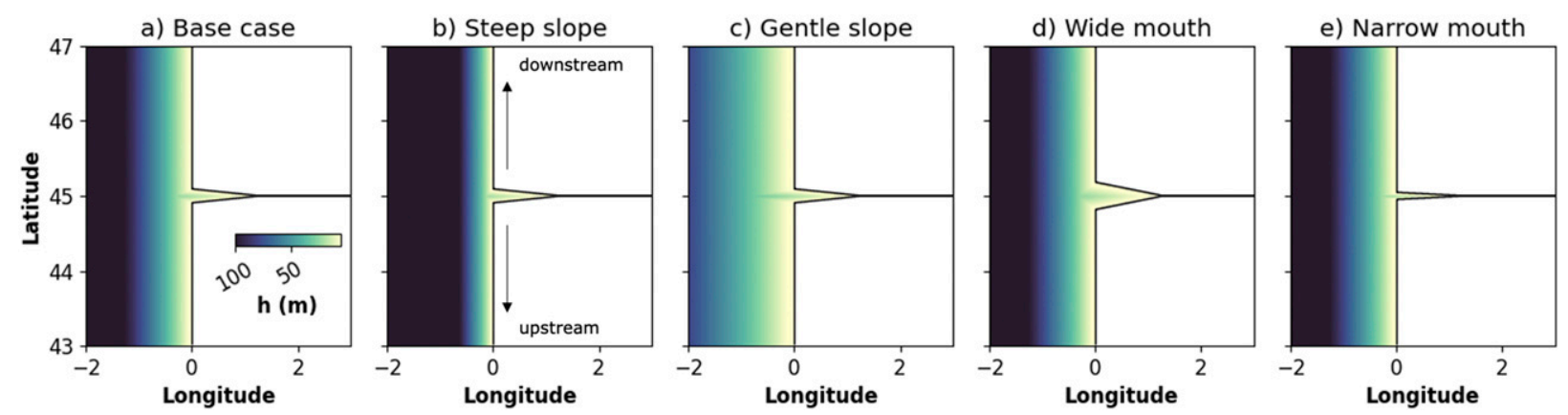

FIG. 1. Bathymetry in model domains.

glacier found that the rate of ambient glacial melt is orders of magnitude larger in the meltwater budget than initial theories predicted (Jackson et al. 2019).

Here we focus on shelf inflow to estuaries whose plumes form approximately geostrophic coastal currents after tidal averaging. This is true when the length scale of the relevant feature (perhaps the width of the plume, mouth, or inflowing current) is larger than the internal Rossby radius of deformation (Garvine 1995). The dynamics of such an estuary are influenced by planetary rotation. Estuaries of this scale are the subject of this study because they generate a larger response on the shelf and because they have been the subject of prior literature on estuarine inflow. In describing results, the terms "downstream" and "upstream" are used in reference to the direction of coastal trapped wave phase propagation (Fig. 1).

Prior work to find the sources of estuarine inflow on the shelf sought analytical solutions in the form of the arrested topographic wave (ATW; Csanady 1978; Beardsley and Hart 1978; Masse 1990). The first analytical approach to the inflow problem was done by Beardsley and Hart (1978), who solved for a steady inflow in the denser lower layer of a two-layer shelf forced by a point sink at the coastline. Inflow felt bottom stress and interfacial stress from the overlying outflow. A later application by Masse (1990) solved for inflow analytically using a one-layer solution to the steady, linearized shallow-water momentum equations from a mouth of finite width, and the solution was generalizable to more complex bathymetries. We will focus our comparisons on the Masse (1990) solution because the physics are demonstrated more clearly, and Masse (1990) is hereafter referred to as the "ATW solution." The ATW solution used a rotating shelf that was uniform in the alongshore direction $(y)$ and linearly sloping in the crossshore direction $(x)$. Momentum was linearized by assuming advective momentum terms were negligible. Friction was linear and only present in the alongshore momentum equation. Inflow occurred in a vertically homogeneous, hydrostatic layer, so pressure gradients were given as sea surface height (SSH) perturbations $\eta$. The resulting equations of motion and continuity were (Masse 1990):

$$
\begin{aligned}
-f v & =-g \frac{\partial \eta}{\partial x}, \\
f u & =-g \frac{\partial \eta}{\partial y}-r \frac{v}{h},
\end{aligned}
$$

$$
\frac{1}{h} \frac{\partial(h u)}{\partial x}+\frac{\partial v}{\partial y}=0
$$

where $u$ and $v$ are the cross-shore and alongshore velocities, respectively; $f$ is the Coriolis parameter; $g$ is gravity; $r$ is a linear friction coefficient; and $h$ is water depth. The continuity equation can be combined with the equations of motion to produce an equation for $\eta$ that has the form of a diffusion equation:

$$
\frac{\partial \eta}{\partial y}=\kappa \frac{\partial^{2} \eta}{\partial x^{2}} .
$$

The diffusion constant $\kappa=r /(f \alpha)$, where $\alpha=-d h / d x$ is the slope of the shelf. Equation (4) can be solved numerically using three boundary conditions: no flow at the upstream boundary, no flow at a distant offshore boundary (not necessarily the offshore boundary of the actual numerical domain), and no cross-shore flow at the coastline except at the estuary mouth, where a fixed cross-shore transport is prescribed across a finite width (described in section 2).

In the ATW solution, estuarine inflow was sourced from downstream of the channel. The system is forced with onshore flow at the mouth, and there is some onshore flow even far down-shelf. This squashes water columns as they move into shallower water [the lhs of Eq. (4)], generating anticyclonic changes to relative vorticity, changes that are balanced by frictional torque from bottom stress [the rhs of Eq. (4)]. The resulting streamlines were almost parallel to isobaths, approaching the estuarine channel at a gentle onshore angle. The flow turned onshore sharply near the mouth so that inflow entered the estuary perpendicular to the coastline (Beardsley and Hart 1978; Masse 1990).

We seek to update the answer to where inflow to estuaries originates on the shelf by using three-dimensional modeling that can resolve many of the dynamics neglected in the ATW solution, most importantly time variance, entrainment between the shelf and the plume, and nonlinear advection terms. The questions this study addresses are

1) Where is the ATW solution applicable?

2) Where do previously neglected dynamics spin up secondary sources of inflow?

Parameter space will be explored in so far as to demonstrate the robustness of the results and dynamical explanations. 


\section{Methods}

To investigate the sources of inflow to an estuary, five models of an idealized estuary were built using the Regional Ocean Modeling Systems (ROMS). ROMS solves the threedimensional Reynolds-averaged Navier-Stokes equations on a stretched vertical coordinate grid (Shchepetkin and McWilliams 2005). The base case model grid used in this study was based on that designed in MacCready et al. (2018) and featured a river flowing out onto an unstratified shelf (shelf salinity $31 \mathrm{~g} \mathrm{~kg}^{-1}$ ) that was linearly sloped (slope of $1 \mathrm{~m}$ per $1 \mathrm{~km}$ offshore distance). The river channel was $\mathrm{V}$-shaped and widened and deepened toward the mouth (Fig. 1a). The mouth in the base case is $2 \mathrm{~km}$ wide. The horizontal grid resolution was highest near the estuary mouth, with a grid cell length of $500 \mathrm{~m}$. Horizontal resolution increased telescopically from the mouth to $2.5 \mathrm{~km}$ near the model edges. The vertical grid had 30 levels that stretched to accommodate bathymetry. Drag is calculated quadratically with a drag coefficient of $3 \times$ $10^{-3}$. Freshwater flowed in through the river channel at a constant rate of $1500 \mathrm{~m}^{3} \mathrm{~s}^{-1}$. Boundary conditions at the three open-ocean boundaries (offshore, upstream, and downstream) followed Chapman (1985) for the surface elevation and Flather (1976) for momentum terms. All of the models used a singlefrequency, 12-h tidal forcing, imposed using sea surface height (SSH) at the open boundaries. Vertical mixing was modeled using the $k-\varepsilon$ turbulence closure parameters with the CanutoA stability functions (Umlauf and Burchard 2003). There were no shelf currents or winds. This simplified forcing scheme was used as a starting point to isolate the processes drawing shelf water into the estuary.

After the base case, four additional models were run: two variations on the shelf slope $\left[2 \mathrm{~m}(1 \mathrm{~km})^{-1}\right.$, "steep slope," Fig. $1 \mathrm{~b} ; 0.5 \mathrm{~m}(1 \mathrm{~km})^{-1}$, "gentle slope," Fig. 1c] and two variations on the river mouth width $(40 \mathrm{~km}$, "wide mouth," Fig. $1 \mathrm{~d}$; $10 \mathrm{~km}$, "narrow mouth," Fig. 1e). The five models were each run for 120 model days, with averaging of model fields and particle releases done over the final 75 days.

\section{a. Reproducing the ATW solution}

For comparison between the ROMS model and the ATW solution used in previous literature, the streamfunction was calculated using a forward-Euler finite-difference scheme following the forcing setup in Masse (1990). This was done to demonstrate where the ROMS model results are consistent with the dynamic balance assumed in the ATW solution and where they are not. The volume streamfunction is defined

$$
\frac{d \psi}{d y}=h u, \quad \frac{d \psi}{d x}=-h v
$$

Therefore, $\psi$ was found from $v$ using Eq. (5), and $v$ was found by $\eta$ via Eq. (1). Equation (4) was solved for $\eta$ using a value of $\kappa$ corresponding to parameters in the ROMS base case grid: $\alpha=1 \times 10^{-3}$ and $f=1.0312 \times 10^{-4} \mathrm{~s}^{-1}$. The linear drag coefficient for was set to $r=3 \times 10^{-4} \mathrm{~m} \mathrm{~s}^{-1}$, which was estimated from the quadratic drag coefficient of $3 \times 10^{-3}$ used in the ROMS base case multiplied by a typical velocity scale of $0.1 \mathrm{~m} \mathrm{~s}^{-1}$. The grid had the same shelf area as the base case grid but a lower horizontal resolution, with $\Delta x=3290 \mathrm{~m}$ and $\Delta y=889 \mathrm{~m}$. This asymmetric grid resolution fulfilled the Courant stability requirement for solving Eq. (4) in an explicit time stepping, $C=\kappa \Delta y / \Delta x^{2} \leq 0.5$.

Forcing at the coastal boundary followed Masse (1990). In summary, Eqs. (1) and (2) are combined and an assumption was made that as depth shoaled at the coastline $h \rightarrow 0$, transport across the mouth stayed finite, $h u \rightarrow Q_{\text {in }} / w$. The boundary condition for flow into the estuary mouth was

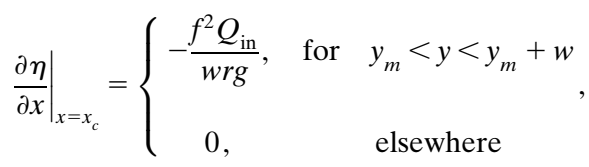

where $x_{c}$ is the location of the coastal boundary, $y_{m}$ is the location of the upstream edge of the estuary mouth, and $w$ is the mouth width $(20 \mathrm{~km})$. The value of $Q_{\text {in }}$ was derived using the transport across the estuary mouth in the ocean model calculated by the total exchange flow method (described below).

In the ocean model output, the "coastline" for the inflowing current is effectively the plume front. This is because the inflowing current is blocked where plume is attached to the seafloor. When comparing the reproduced ATW solution with the ocean model output, the ATW results will be shifted offshore by the mean extent of the plume base, defined as where seafloor salinity is fresher than the shelf salinity by $0.1 \mathrm{~g} \mathrm{~kg}^{-1}$ or more.

To identify the estuary-bound current on the shelf, particle tracking and integrated volume transport perspectives were used. That is, inflow was depicted in one analysis as Lagrangian streamlines and in the second analysis as the volume of flow across a cross section.

\section{b. Particle tracking analysis}

For the Lagrangian analysis, particles were released onto the shelf and passively advected by the shelf currents. Their paths were tracked, and the tracks were filtered by whether the particles reached water with salinity fresher than $25 \mathrm{~g} \mathrm{~kg}^{-1}$. This salinity was only present within the estuarine channel and therefore indicated that a particle had been advected into the channel and underwent mixing. Particle tracking was implemented in an offline model that utilized the output of the ocean model. Particle positions were advected using nearestneighbor interpolation of three-dimensional velocity fields in the hourly ocean model output. The integration methods were similar to those used in previous studies (Banas et al. 2009; Giddings et al. 2014; Brasseale et al. 2019). Tracks were calculated by forward integration in time (with a 300-s time step) using fourth-order Runge-Kutta integration. Particles were dispersed vertically according to a random walk model developed by Visser (1997) to simulate the effect of vertical turbulent mixing. Vertical eddy viscosity was smoothed using a three-point Hanning window prior to calculation of vertical gradients as part of the turbulent displacement algorithm, similar to the smoothing employed in North et al. (2006).

The particles were released in the model after a 45-day spinup period and were tracked for 75 days. 12000 particles were released, distributed across 1200 latitude-longitude pairs 
and 10 depths that were spaced evenly throughout the water column. This was done to ensure that boundary layers were resolved at all locations but resulted in a higher vertical density of particles released in the shallower water near the coast.

\section{c. Particle track momentum balances}

To understand the physics of inflow as it moved across the shelf, a momentum budget was calculated along the inflowing particles' paths. This was done using ROMS diagnostic output, using saved terms in the Navier-Stokes equations, which ROMS calculates to update the modeled flow field. ROMS uses the hydrostatic approximation and mixing from horizontal shear is neglected.

$x$-direction momentum:

$$
\begin{gathered}
\underbrace{\frac{1}{\delta} \frac{\partial(\delta u)}{\partial t}}_{\text {u_accel }}+\underbrace{\frac{\partial}{\partial x}\left(u^{2}\right)}_{\text {u_xadv }}+\underbrace{\frac{\partial}{\partial y}(u v)}_{\text {u_yadv }}+\underbrace{\frac{\partial}{\partial z}(u w)}_{\text {u_vadv }}-\underbrace{f v}_{\text {u_cor }} \\
=\underbrace{-\frac{1}{\rho_{0}} \frac{\partial p}{\partial x}}_{\text {u_prsgrd }}+\underbrace{\frac{\partial}{\partial z}\left(A \frac{\partial u}{\partial z}\right)}_{\text {u_vvisc }},
\end{gathered}
$$

$y$-direction momentum:

$$
\begin{gathered}
\underbrace{\frac{1}{\delta} \frac{\partial(\delta v)}{\partial t}}_{\text {v_accel }}+\underbrace{\frac{\partial}{\partial x}(v u)}_{\text {v_xadv }}+\underbrace{\frac{\partial}{\partial y}\left(v^{2}\right)}_{\text {v_yadv }}+\underbrace{\frac{\partial}{\partial z}(v w)}_{\text {v_vadv }}+\underbrace{f u}_{\text {v_cor }} \\
=\underbrace{-\frac{1}{\rho_{0}} \frac{\partial p}{\partial y}}_{\text {v_prsgrd }}+\underbrace{\frac{\partial}{\partial z}\left(A \frac{\partial v}{\partial z}\right)}_{\text {v_vvisc }},
\end{gathered}
$$

where $\delta$ is the grid cell height; $u, v$, and $w$ are the $x$-, $y$-, and $z$-direction velocities, respectively; $\rho_{0}$ is the background density; $p$ is the hydrostatic pressure; and $A$ is the eddy diffusivity. ROMS outputs diagnostic terms [term names are given in Eqs. (7) and (8)] at a time step halfway between the output schedules of the ocean model and the particle tracks. To generate a history of forcing experienced by the particle, the forcing variables from the diagnostic output at the particle's location were averaged from the output files $30 \mathrm{~min}$ before and $30 \mathrm{~min}$ after the particle's time step.

The momentum equations were translated into a Lagrangian reference frame and rotated into a streamwise-normal $(s-n)$ coordinate system, following the $s-n$ coordinate momentum balances of Hench and Luettich (2003) and McCabe et al. (2009). The translation of the equations from an Eulerian to Lagrangian reference frame was done by adding the local acceleration to the advective terms to form the material derivative of velocity with respect to time. The material derivative corresponded to the particle's change in speed. The $s-n$ coordinate system was defined for each particle such that the streamwise direction $s$ was directed along the track the particle was traveling and the normal coordinate $n$ was perpendicular to the particle track everywhere. The velocity in the streamwise direction $u_{s}$ was the speed at which the particle was traveling and the velocity in the normal direction $u_{n}$ is zero by definition. A variable $\theta$ was defined as the angle between the $x-y$ coordinate system and the $s-n$ coordinate system. The vertical coordinate $z$ was unchanged. After translation and rotation, the momentum equations in the $s-n$ coordinate system were

$s$-direction momentum:

$$
\frac{D u_{s}}{D t}=-\frac{1}{\rho_{0}} \frac{\partial p}{\partial s}+\frac{\partial}{\partial z}\left(A \frac{\partial u_{s}}{\partial z}\right)
$$

n-direction momentum:

$$
u_{s} \frac{D \theta}{D t}=f u_{s}-\frac{1}{\rho_{0}} \frac{\partial p}{\partial n}+A \frac{\partial u_{s}}{\partial z} \frac{\partial \theta}{\partial z} .
$$

The terms in the $s$-direction momentum equation are the streamwise acceleration, the streamwise pressure gradient, and friction arising from vertical divergence of streamwise stress. The terms in the $n$-direction momentum equation are the change in particle direction, the Coriolis force, the streamnormal pressure gradient, and friction. For more information about the derivation of the $s-n$ coordinate momentum equations, see previous work in the appendix of Hench and Luettich (2003) for the derivation and McCabe et al. (2009) for a vertically resolved generalization.

After the time series of momentum terms were extracted from the model output for each particle's track, the terms in Eqs. (9) and (10) and the particle position were tidally averaged using a Godin filter (Godin 1972) before being rotated into the $s-n$ coordinate system for each step of each particle's time series. The streamwise direction relative to the $x-y$ coordinate system $\theta$ was inferred from the direction of the Coriolis force vector, which was always stream-normal. To compare a diversity of curving particle tracks, the momentum series were plotted with particle positions normalized by their streamwise distance from a reference point at the channel mouth.

\section{d. Transport analysis}

To complement the particle tracking analysis, inflow was analyzed as transport of the volume of shelf water toward the estuary. Transport calculations were performed using the total exchange flow method, or TEF (MacCready 2011). TEF was developed to translate flow fields in estuaries into a framework based on the Knudsen relations (Knudsen 1900; translated in the appendix of Burchard et al. 2018). That is, TEF deconstructs flow at a cross section of an estuary, no matter how complex, into two layers using salinity classes: a salty layer transporting salt up-estuary, and a fresher layer of mixed water transporting salt out of the estuary. This was done by determining a dividing salinity to separate water masses responsible for up-estuary salt flux from down-estuary salt flux (MacCready et al. 2018; Lorenz et al. 2019). Here we extended TEF to the shelf. A shelf with an abutting estuary was assumed 

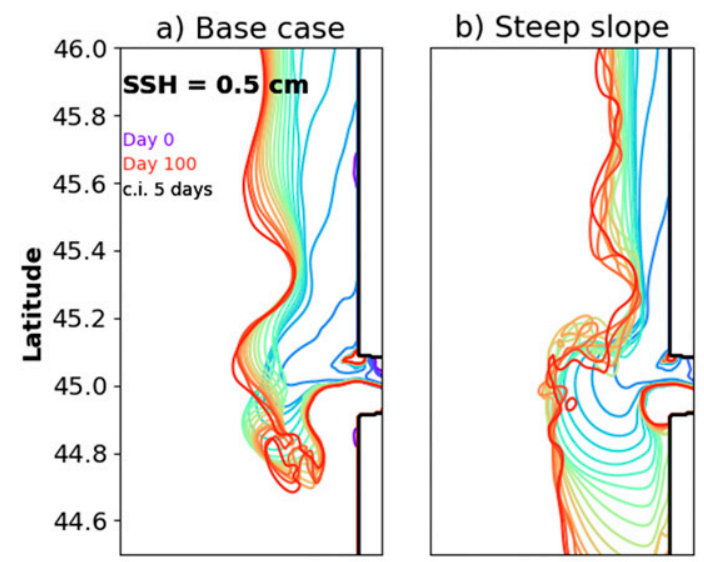

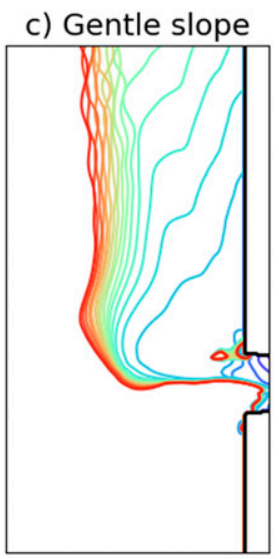

d) Wide mouth
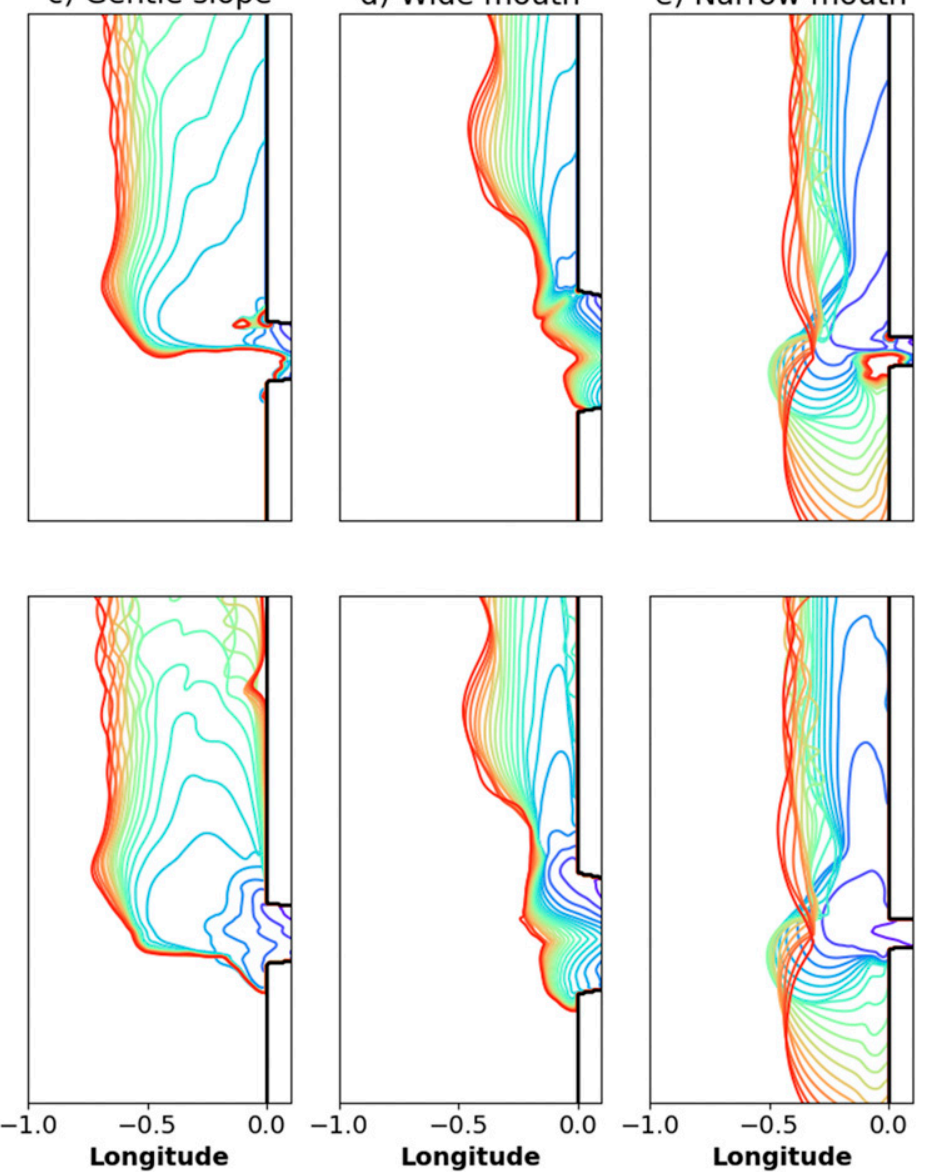

e) Narrow mouth

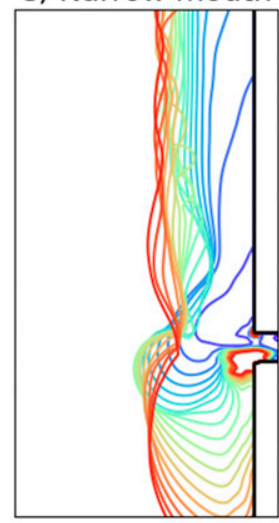

Longitude
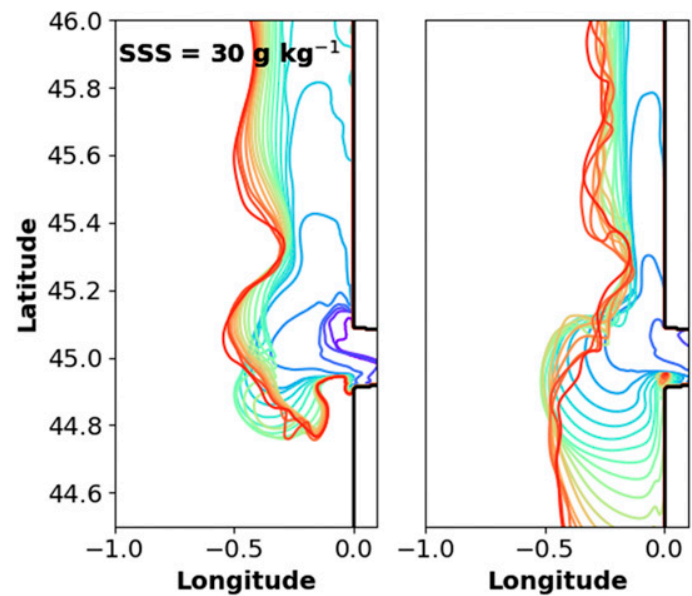

FIG. 2. Time evolution of the (top) $0.5 \mathrm{~cm} \mathrm{SSH}$ contour and (bottom) $30 \mathrm{~g} \mathrm{~kg}^{-1} \mathrm{SSS}$ contour for (a)-(e) each of the five models. Contours go from day 0 to day 100 at an interval of 5 days.

to have two fundamental water masses: dense shelf water transporting salt toward the estuary, and buoyant plume water traveling away from the estuary. Transport was estimated across 10 cross sections through the estuary and ten on the shelf. On the shelf, the cross sections were drawn as boxes centered on the estuary such that TEF transports were evaluated using salt flux into and out of the box, in analogy to salt flux up-estuary and down-estuary. Flow was sorted on the three sides of the shelf box using a single dividing salinity for each box.

\section{Results}

For the base case, exchange within the estuary was typical of a partially mixed estuary in the Geyer and MacCready (2014) parameter space, with a freshwater Froude number of $1 \times 10^{-2}$ and a mixing parameter of 0.74 . The outflow flowed out onto the shelf in a buoyant plume and traveled downstream from the channel to form a coastal current (Fig. 2). Exchange flow began on the shelf as the plume nose arrived (inflow across the shelf box in Fig. 3 became nonzero at the same time that the outflow did, around day 30).

\section{a. Estimating exchange flow on the shelf}

Magnitudes of time-averaged transport of shelf water and mixed plume water were calculated across a series of cross sections in the channel and across boxes drawn on the shelf (Fig. 4). The net transport across all cross sections was $1500 \mathrm{~m}^{3} \mathrm{~s}^{-1}$, which was required for mass conservation of the river input of $1500 \mathrm{~m}^{3} \mathrm{~s}^{-1}$ into the model. The magnitudes of transport of dense water into and buoyant water out of the cross sections increased with distance from the freshwater source (Fig. 4b). Transport magnitudes increased monotonically in the estuary, consistent with earlier model simulations (MacCready 2011). We also found that exchange transport continued to increase monotonically on the shelf.

\section{b. Inflow paths}

Inflow was analyzed from a Lagrangian perspective using particle tracks. Particles were released on the shelf and considered to be inflow if they reached water of salinity fresher than $25 \mathrm{~g} \mathrm{~kg}^{-1}$, a condition only found in the estuarine channel. Three particle groups were identified: downstream particles, plume particles, and upstream particles. Downstream particles followed a cyclonic path similar to the ATW solution offshore 


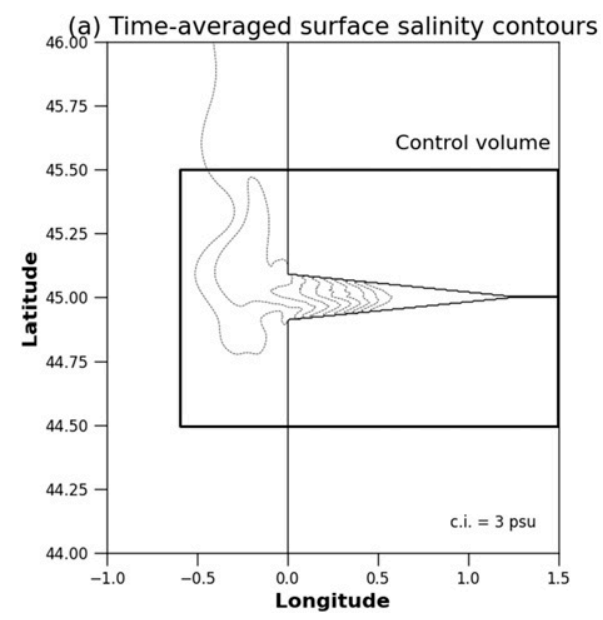

(b) TEF Salt budget

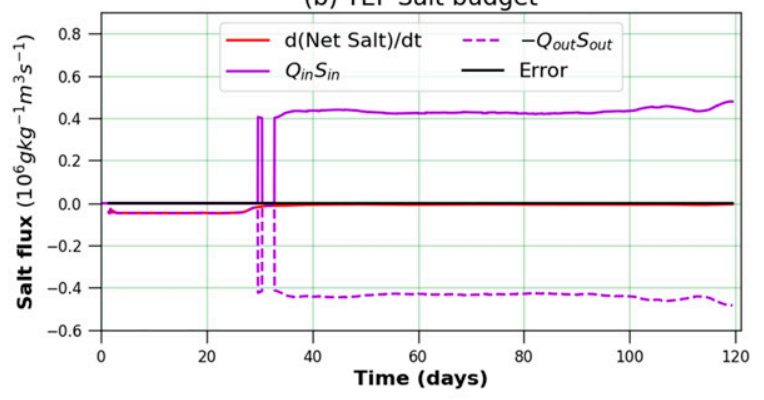

FIG. 3. (a) Salinity fluxes within a control volume depicted by a box around the time-averaged surface salinity and (b) a plot of evolution in time of transport of salinity into the volume $\left(Q_{\mathrm{in}} S_{\mathrm{in}}\right)$, transport of salinity out of the volume $\left(-Q_{\text {out }} S_{\text {out }}\right)$, the change in salt within the control volume $[d($ Net Salt $) / d t]$, and the error.

of the plume (Fig. 5a). Plume and upstream particles arose from dynamics not captured in the ATW solution. Plume particles originated within the buoyant plume, and these particles each had an initial salinity at least $0.1 \mathrm{~g} \mathrm{~kg}^{-1}$ fresher than shelf water (Fig. 5b). Upstream particles were sourced from upstream of the estuarine channel, determined arbitrarily to be south of latitude 44.85 (Fig. 5c). In the base case, the upstream group was the least populated, while the plume and downstream groups had similar populations (Fig. 6). Note that group population does not translate directly to the relative magnitudes of transport, as particles do not represent volumes and were distributed more densely in shallow water.

To explore the robustness of the plume and upstream inflow paths, additional models were run that varied the shelf slope and the estuarine mouth width. The plume path was present all cases except the wide mouth case, where it was significantly diminished (Figs. 6 and 7d). The upstream path was present in all models but differed in the direction of approach. Particles in the upstream group approached anticyclonically in the base case, the steep slope case, and the narrow mouth case (Figs. 7a,b,e), and in each of these cases the upstream group was the least
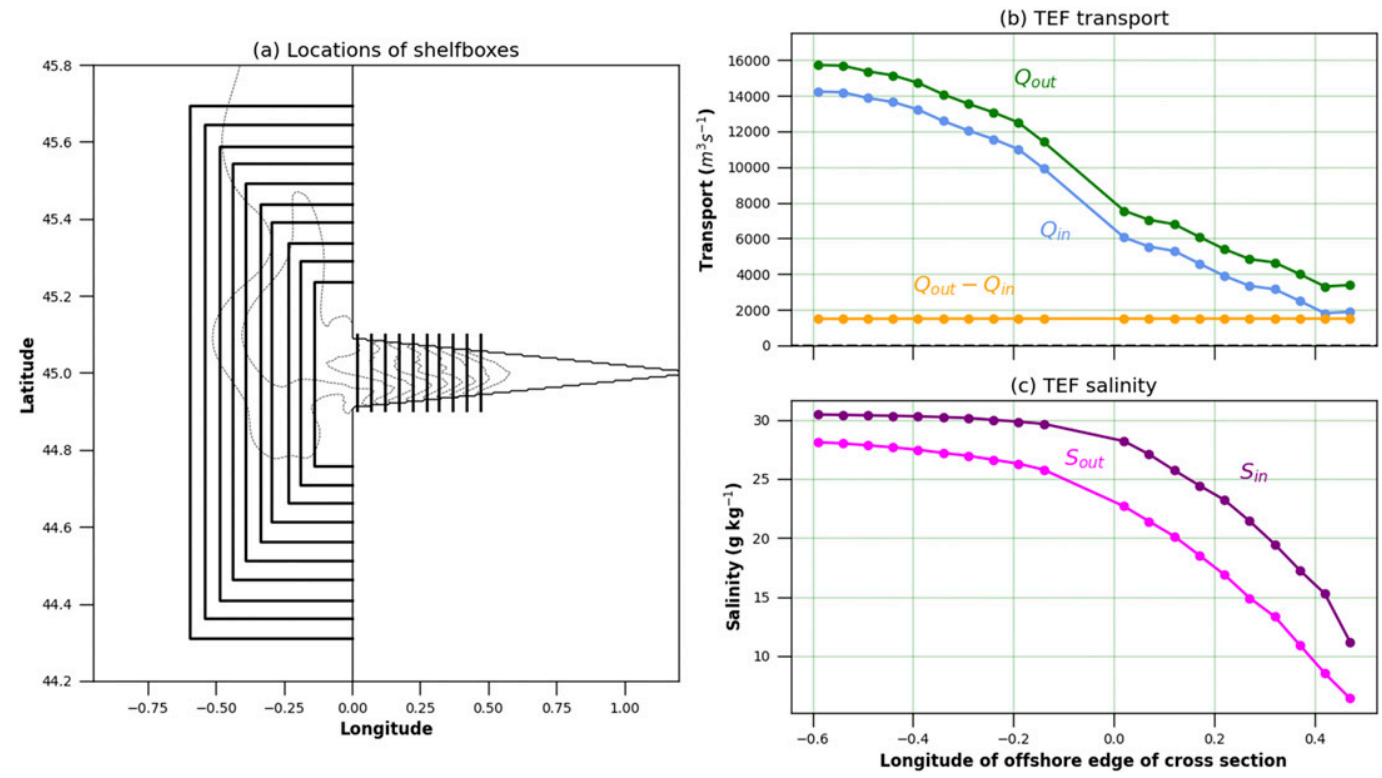

FIG. 4. Time-averaged TEF quantities calculated in the estuarine channel and on the shelf. (a) The locations of the shelf boxes and estuary sections with the time-averaged surface salinity (contoured as in Fig. 3a). (b) The volume transports into and out of and the net transport across each shelf box or estuary section. (c) The fluxweighted salinity of flow into and out of each shelf box or estuary section. 

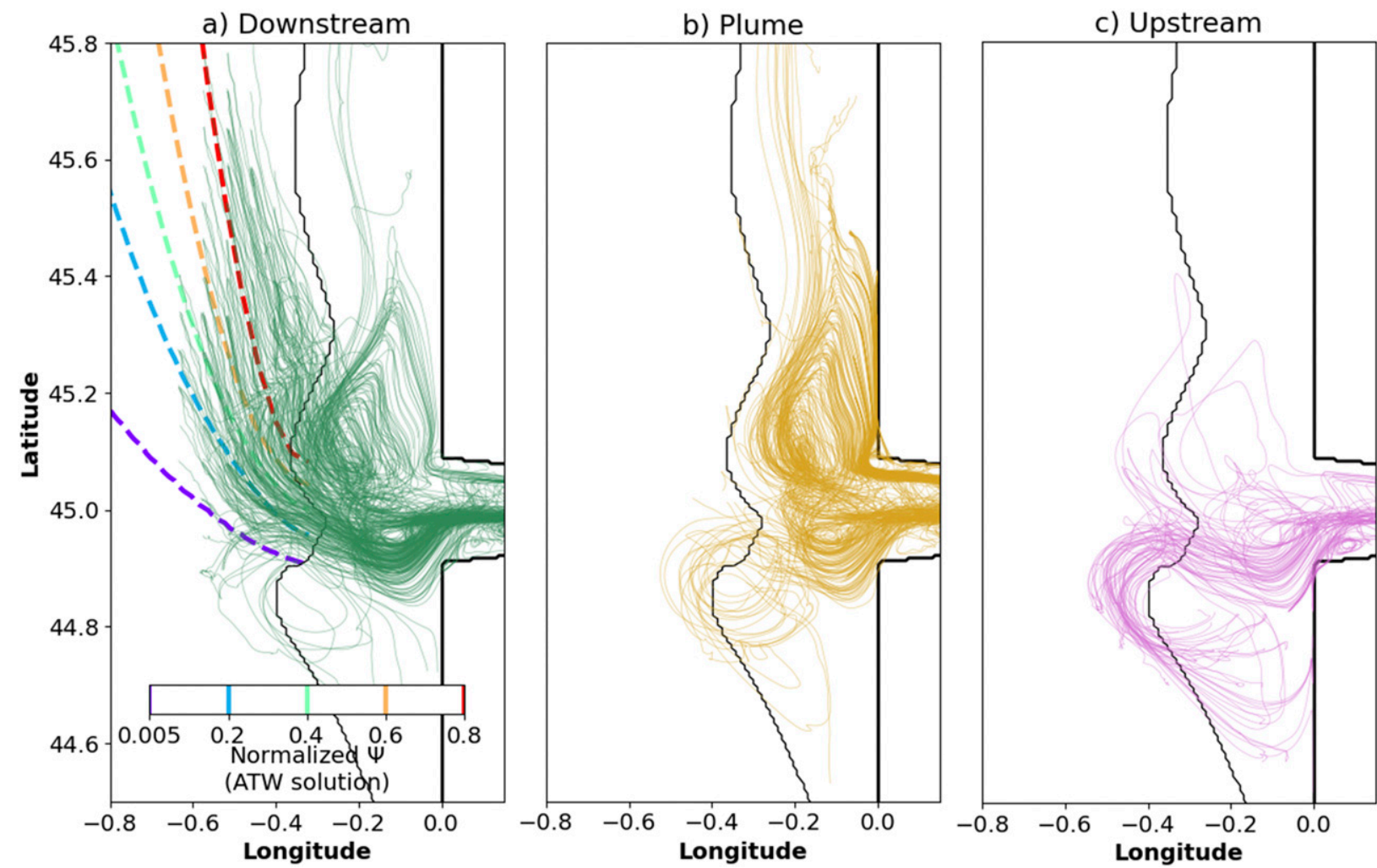

FIG. 5. Base case inflowing particle paths plotted in plan view after tidal smoothing with a Godin filter sorted into three groups (as described in text). The seafloor salinity of $30.9 \mathrm{~g} \mathrm{~kg}^{-1}$ is contoured in black, indicating the extent of the plume. (a) The particle paths in the downstream particle group (green lines) with the streamfunction produced by the ATW solution overlayed (colored dashed lines), (b) the plume group (yellow lines), and (c) the upstream group (pink lines).

populated particle group (Fig. 6). Upstream particles approached cyclonically in the gentle slope case and the wide mouth case (Figs. 7c,d), and the upstream group was more populated in these cases (Fig. 6).

\section{c. Inflow depth}

Inflow originated from all depths of the water column, consistent with expectations for an unstratified shelf. This was seen in the particle tracking analysis, as particles that were drawn into the estuary from the shelf occupied all depths before tidal averaging (Fig. 8a). This result differs when the particle tracks were tidally smoothed using a Godin filter. After tidal smoothing, a preference emerged for middepths. Even though particle tracks occupied the bottom boundary layer before tidal smoothing, no tracks appeared in the bottom boundary layer after tidal smoothing (Fig. 8b). This was because vertical shear in boundary layers induced vertical mixing, so the particles could not reside in the boundary layers for very long.

Inflowing currents were fastest beneath the tilted isopycnals of the plume-shelf interface in all models (Fig. 9). Even at its fastest, the inflowing current was slower than the outflowing current of the river plume. In the base case, the inflowing current beneath the plume was between 1 and $2 \mathrm{~cm} \mathrm{~s}^{-1}$, much slower than the plume velocity, which exceeded $15 \mathrm{~cm} \mathrm{~s}^{-1}$.

\section{Discussion}

\section{a. Downstream inflow path}

The particles in the downstream group flowed toward the estuary in a shelf current flanked by the plume front and extending offshore (Fig. 5a). Flow in this part of the shelf is

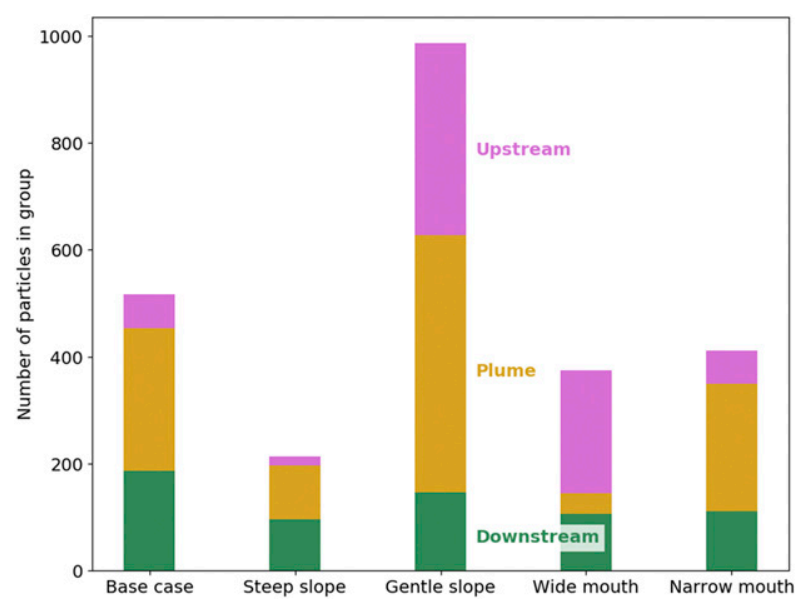

FIG. 6. The number of particles in the three groups for the five models. 

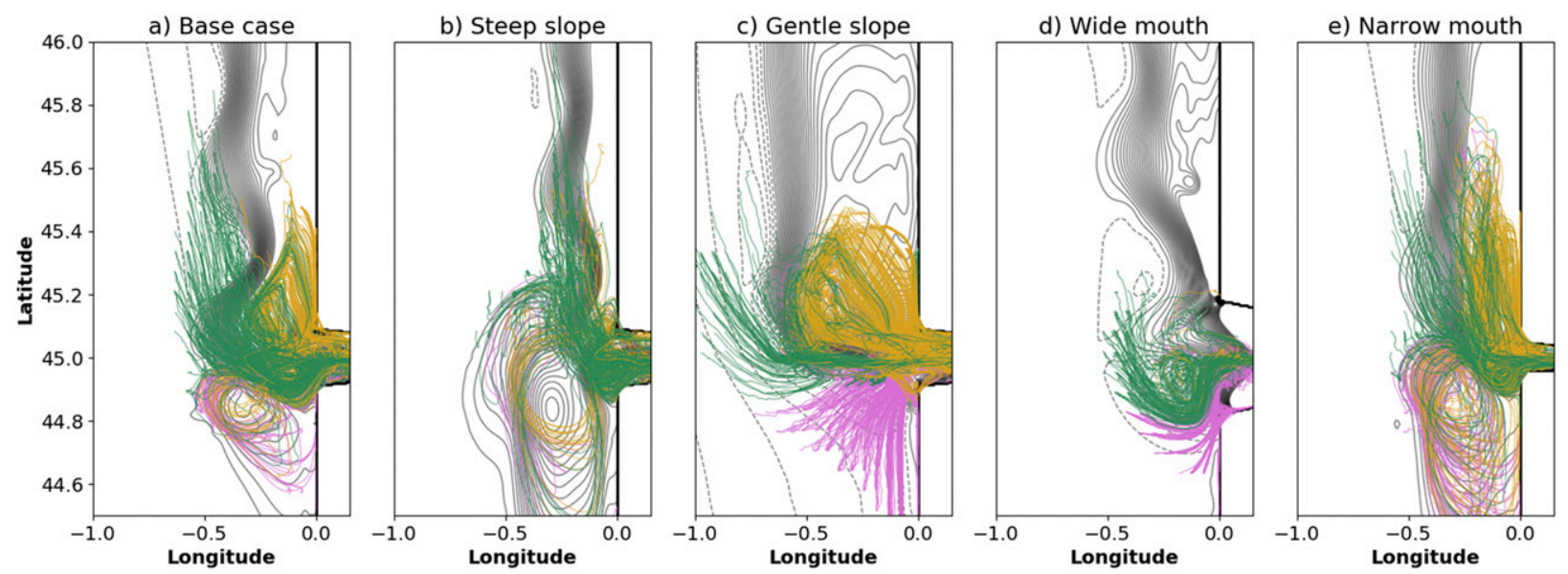

FIG. 7. Inflowing particle tracks (colored lines) plotted over time-averaged SSH (black lines, contoured from -2 to $25 \mathrm{~mm}$, contour interval $=1 \mathrm{~mm}$, dashed lines = negative SSH) for five different model runs. Particles tracks are colored by their inflow path.

mostly in geostrophic balance (Fig. 10a) until it reaches the bulge and nears the mouth. This analysis will focus on the shelf current outside of the bulge.

Alongshore friction allows the shelf current to cross isobaths while conserving potential vorticity (Beardsley and Hart 1978; Masse 1990). The necessary friction is on average an order of magnitude smaller than the geostrophic terms. From Eqs. (1) and (2), the ratio of alongshore friction to cross-shore Coriolis is $r /(f h)$. Using $h=30 \mathrm{~m}$ and the values $r=3 \times 10^{-4} \mathrm{~m} \mathrm{~s}^{-1}$ and $f=1.0312 \times 10^{-4} \mathrm{~s}^{-1}$ used in the ATW model, the friction term is one-tenth of Coriolis. The vertically integrated alongshore friction equals or surpasses this scale (Fig. 11; compare blue line to dashed line in right column).

The downstream inflow path partially underlaps the buoyant coastal current, but this has a surprisingly small impact on the

\section{(a) Particle paths in profile}
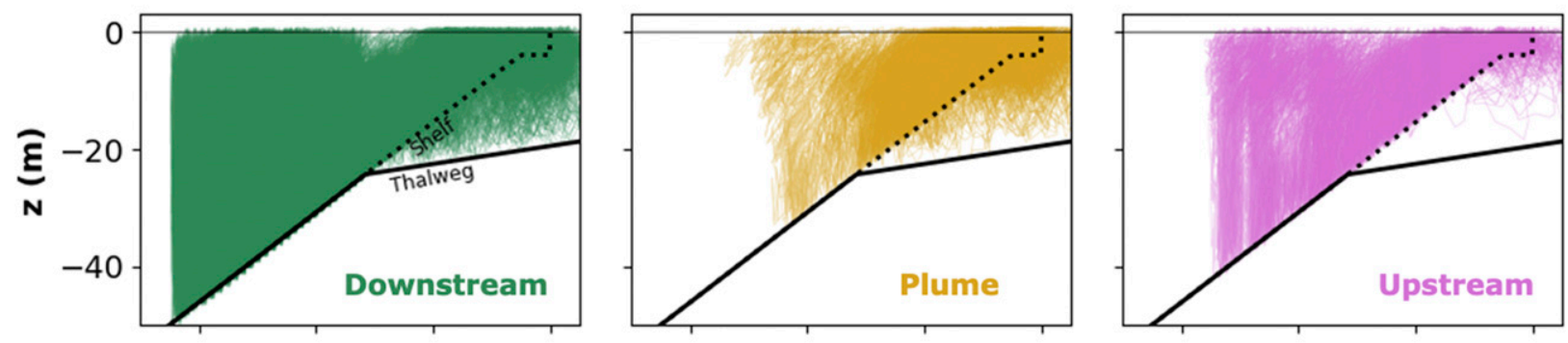

(b) Tidally-smoothed particle paths in profile
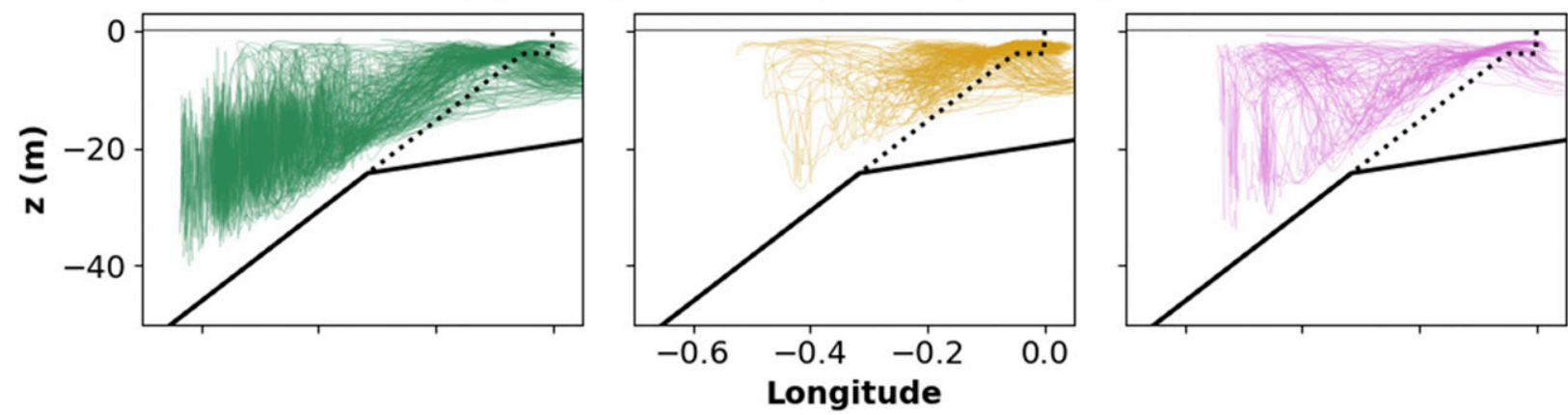

FIG. 8. Base case inflowing particle paths plotted in profile (a) before and (b) after tidal smoothing with a Godin filter. Particles are plotted separately by their inflow path. 

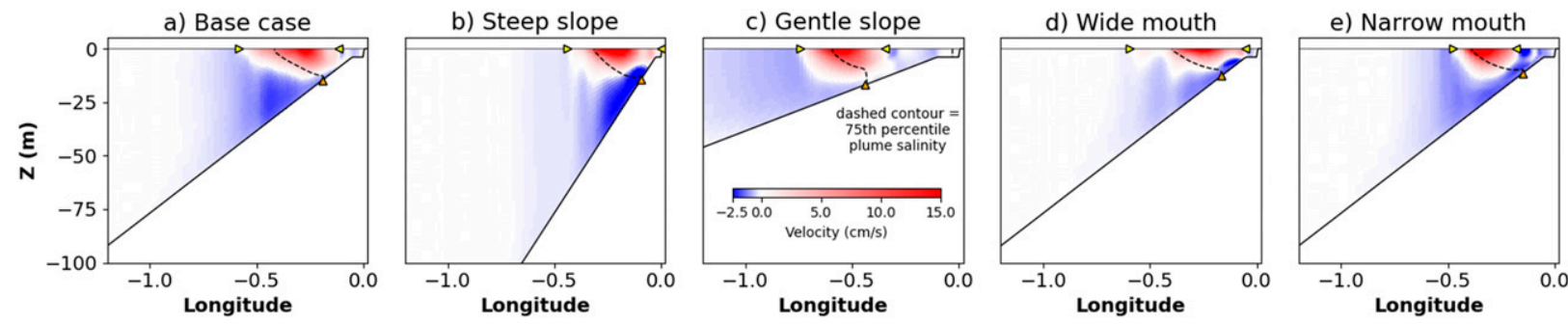

FIG. 9. Time-averaged alongshore velocity at a plume cross section drawn at latitude $45.5^{\circ}$ for the five models. The dashed line indicates the isohaline of the 75th percentile of plume salinity. The yellow and orange triangles indicate where the width and depth of the plume were estimated for Fig. 13.

geometry of the front. This can be demonstrated using the Margules relation for two-layer flow. Thermal wind balance relates the slope of the front to the velocity difference between the currents (Margules 1906):

$$
v_{\text {out }}-v_{\text {in }}=\frac{g^{\prime}}{f} \frac{\Delta z}{\Delta x}
$$

where $v_{\text {out }}$ is the velocity above the front, $v_{\text {in }}$ is the velocity beneath the front, $g^{\prime}$ is the reduced gravity, $\Delta z$ is the front depth, and $\Delta x$ is the front width. The velocities are assumed to be uniformly distributed over the areas of the layered flow at the front such that $v_{\text {out }}=2 Q_{\text {out }} /(\Delta x \Delta z)$ and $v_{\text {in }}=2 Q_{\text {in }}^{\prime} /[\Delta x(\Delta z+\alpha \Delta x)]$, where $Q_{\text {in }}^{\prime}$ is the fraction of the inflow volume found beneath the front (based on areas depicted in Fig. 12). Classic river plume studies neglect shelf currents (Chapman and Lentz 1994; Yankovsky and Chapman 1997; Lentz and Helfrich 2002), which is equivalent to setting $v_{\text {in }}=0$ in Eq. (11). Using this assumption, an expression can be derived for plume depth in terms of plume transport over a quiescent shelf:

$$
\Delta z=\sqrt{\frac{2 Q_{\mathrm{out}} f}{g^{\prime}}} .
$$

When shelf currents are not neglected, the result is a cubic function in $\Delta z$ which contains factors of $\Delta x$ :

$$
\Delta z^{3}+\alpha \Delta x \Delta z^{2}+\frac{2 f}{g^{\prime}}\left(Q_{\text {in }}^{\prime}-Q_{\text {out }}\right) \Delta z-\frac{2 f Q_{\text {out }}}{g^{\prime}} \alpha \Delta x=0
$$
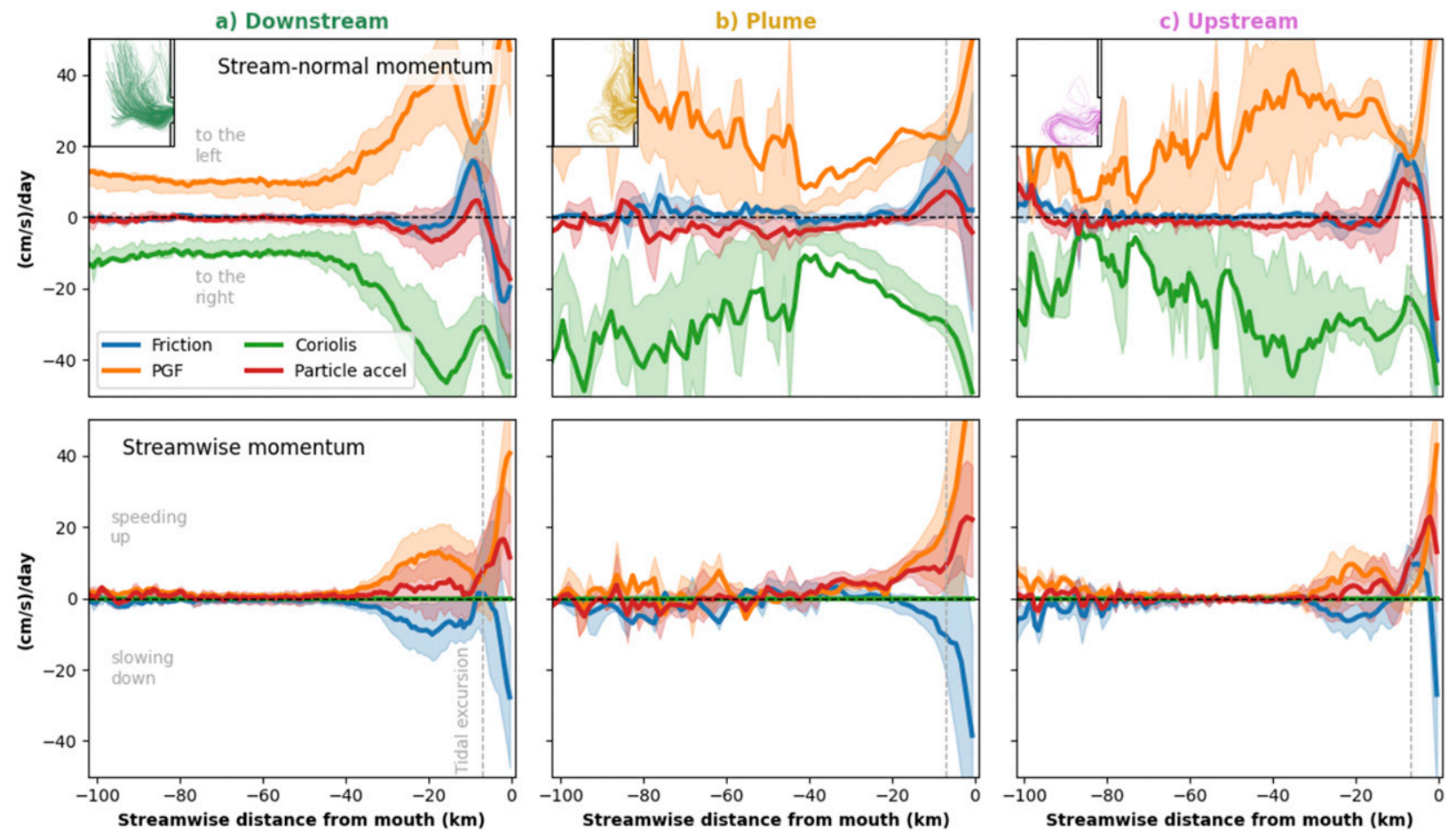

FIG. 10. The momentum terms along particle paths for each of the three particle groups (a) downstream, (b) plume, and (c) upstream, averaged over all particles in the group. The collection of paths used is depicted in insets. Momentum is divided into (top) stream-normal and (bottom) streamwise components. The solid line is the mean value for particles at that distance from the mouth and the shading depicts the spread from the 25 th to the 75 th percentiles. The mean is greater than the 75 th percentile where the data are not normally distributed. The dashed gray line indicates the tidal excursion. 

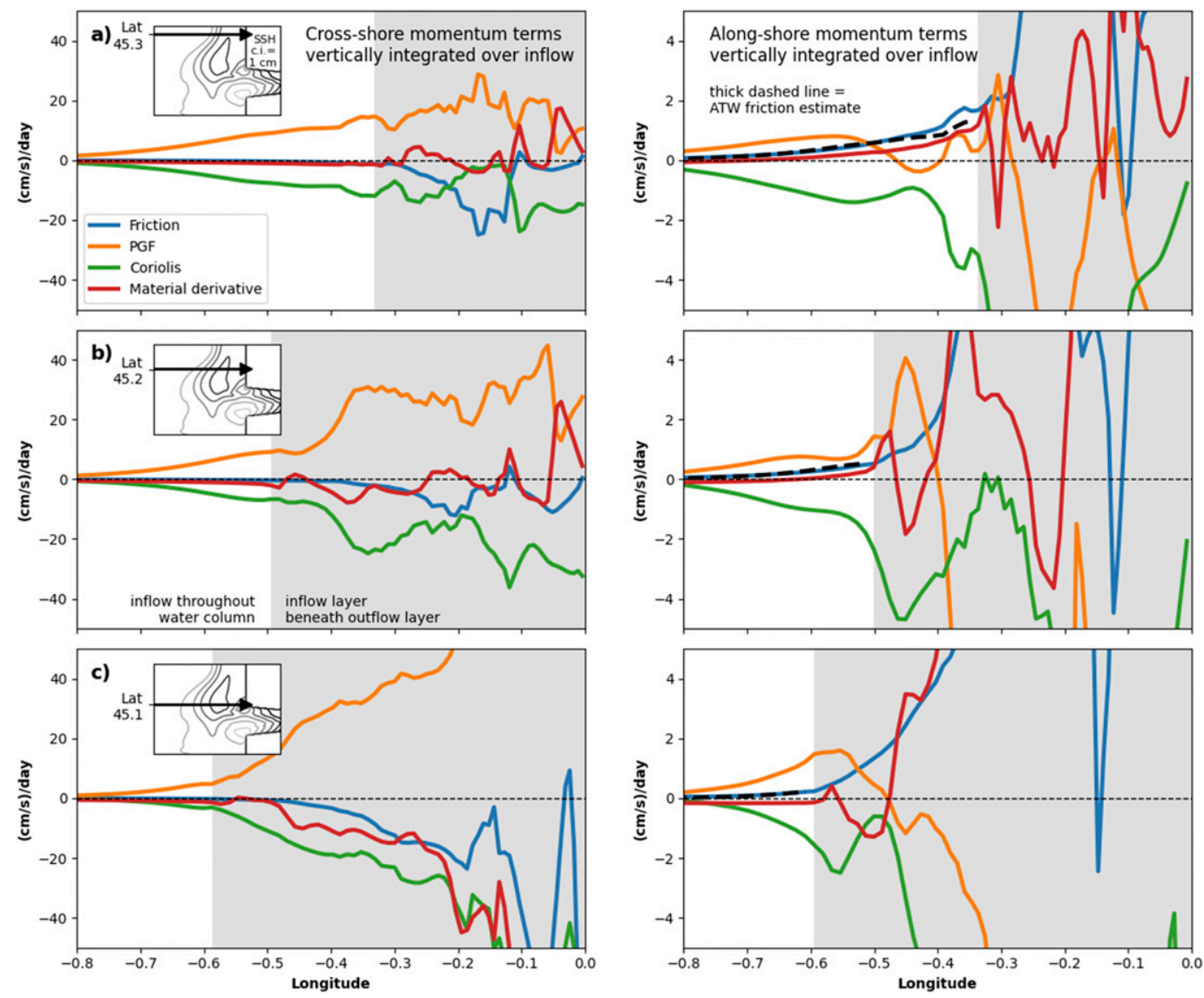

FIG. 11. Time-averaged momentum terms for the base case vertically integrated over inflow $\left(v<0 \mathrm{~m} \mathrm{~s}^{-1}\right)$ at three cross sections downstream of the channel taken at latitudes (a) $45.3^{\circ}$, (b) $45.2^{\circ}$, and (c) $45.1^{\circ}$, with columns showing (left) cross-shore momentum and (right) alongshore. Location of cross sections is plotted in insets with timeaveraged SSH contoured at $1 \mathrm{~cm}$ intervals, and greater SSH shown as darker contours. Data are noisier beneath the plume (gray shaded area), as the inflow layer becomes only a few grid cells thick. The $Y$-axis limits are smaller on right-hand plots to magnify the alongshore friction needed to satisfy ATW dynamics, estimated by a dashed black line offshore of the plume where the ATW solution would be valid.

For the modeled plumes, $\Delta x$ varies in time and with alongshore distance (Fig. 2). To compare Eqs. (12) and (13), it is assumed that $\Delta x$ is proportional to the Rossby radius of deformation,

$$
\Delta x=4.24 \sqrt{g^{\prime} \Delta z} / f,
$$

where the factor of 4.24 is taken from the scaling arguments in Yankovsky and Chapman (1997). Using this, an expression for $\Delta z$ can be found for a front over an inflowing current:

$$
\Delta z^{5 / 2}+\frac{4.24 \alpha g^{1 / 2}}{f} \Delta z^{2}+\frac{2 f}{g^{\prime}}\left(Q_{\mathrm{in}}^{\prime}-Q_{\text {out }}\right) \Delta z^{1 / 2}-\frac{8.48 \alpha Q_{\text {out }}}{g^{1 / 2}}=0,
$$

which is a function of only $Q_{\text {out }}$ and $Q_{\text {in }}^{\prime}$, since $g^{\prime}$ is a function of $Q_{\text {out }}$ for a given river transport and shelf salinity.

To demonstrate the impact of including inflow in the river plume schematic, Eq. (15) was solved numerically for plume depth in two asymptotic end limits. The first was $Q_{\mathrm{in}}^{\prime}=0$, where there was no inflowing current under the plume [equivalent to Eq. (12)]. The second was $Q_{\mathrm{in}}^{\prime}=Q_{\text {out }}$, so the volume transport under the plume was equal to plume transport. This is the asymptotic limit for large exchange flow $\left(Q_{\text {in }}, Q_{\text {out }} \gg Q_{\text {riv }}\right)$. This is approximately true in the base case model, where the calculated $Q_{\text {in }}$ and $Q_{\text {out }}$ were 10 times larger than the net transport at the outermost shelf box (Fig. 4b). However, this end limit also requires the assumption that all inflow was transported beneath the plume front $\left(Q_{\mathrm{in}}^{\prime}=Q_{\text {in }}\right)$. Therefore, $Q_{\mathrm{in}}^{\prime}=Q_{\text {out }}$ is an upper bound which overestimates transport under the plume. Even when overestimated, the theory demonstrates that $Q_{\text {in }}^{\prime}$ increases the depth of the plume by only $10 \%-20 \%$ (Fig. 13a).

Although the difference is small, the Eq. (15) does a better job of predicting plume depth in the ocean models than Eq. (12). The two predictions were evaluated against the plume depth and transport in the three-dimensional ocean model output averaged over plume cross sections from latitudes 45.5 to 46.0. Plume transport was calculated by multiplying the velocity 
(a) River plume with no inflow

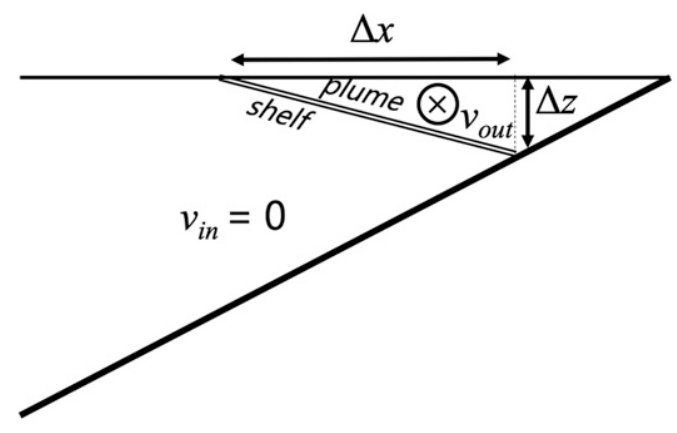

(b) River plume with inflow

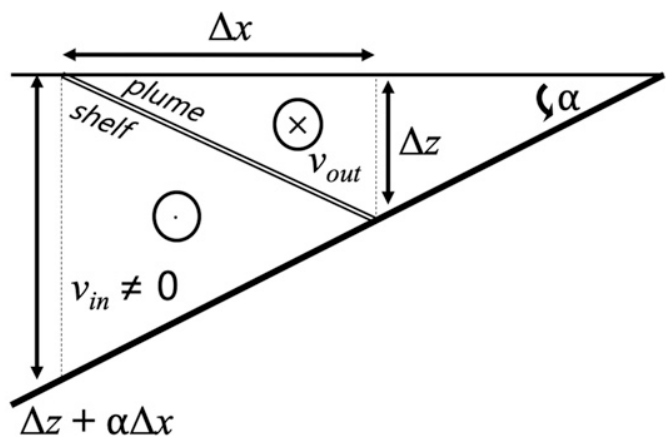

FIG. 12. Schematic of (a) the cross section of a river plume with no flow beneath the front and (b) a river plume with an inflowing current that is deeper and wider and has a steeper interface.

times the grid cell volume for all grid cells with positive alongshore velocity and salinity fresher than $30.9 \mathrm{~g} \mathrm{~kg}^{-1}$. The plume depth was calculated using the intersection of an isohaline with the seafloor representing the 75 th percentile of plume salinity, which ranged from 29.25 to $30.2 \mathrm{~g} \mathrm{~kg}^{-1}$ (orange triangles in Fig. 9). Salinity was used to define the bottom of the front because it extends to the seafloor, while the transport does not. The 75 th percentile was chosen over other definitions such as $30.9 \mathrm{~g} \mathrm{~kg}^{-1}$ (which has been used as the cutoff between the plume and the shelf in most of this study) or the mean plume salinity because it qualitatively captured the data best. Using these values of plume depth, the root-mean-square error of Eq. (15) is almost half that of Eq. (12) (Fig. 13a). This would support the hypothesis that inflowing shelf currents deepen the plume through thermal wind shear and that neglecting shelf currents underestimates plume depth, but this result is sensitive to the definition used to derive plume depth from the models.

(a) Plume depth

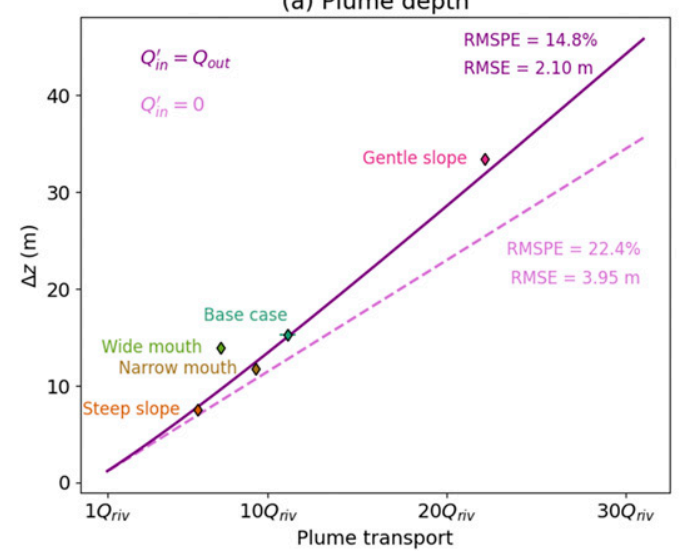

The results from Eq. (14) for $\Delta x$ were $30 \%$ narrower than the average plume widths in the ocean models (Fig. 13b). Sensitivity tests varying $\Delta x$ by $\pm 50 \%$ produced changes of $\pm 5 \%$ in $\Delta z$ when $Q_{\text {in }}^{\prime}=Q_{\text {out }}$, and no change in $\Delta z$ when $Q_{\text {in }}^{\prime}=0$. Therefore, the assumptions behind Eq. (14) do not change the conclusions about plume depth. The large error in $\Delta x$ does indicate the weakness in using a time-invariant model for plume width at the surface, a value that increases monotonically in time (described in Lentz and Helfrich 2002; visible in Fig. 2).

To summarize, the downstream particle group was demonstrated here to be driven by dynamics consistent with the ATW solution, i.e., dominated by geostrophic balance but allowed to cross isobaths by the inclusion of a small amount of alongshore friction. It was also demonstrated that the effect of inflowing transport at the plume front deepens the front by increasing the thermal wind gradient. However, the impact on the river plume depth was only $10 \%-20 \%$, even

FIG. 13. Comparison of theoretical predictions for plume (a) depth and (b) width given by the Margules relation with no transport under the plume, $Q_{\text {in }}^{\prime}=0$ [Eq. (12), light purple dashed line], and inflow transport under the plume equal to plume transport, $Q_{\mathrm{in}}^{\prime}=Q_{\text {out }}$ [Eq. (15), dark purple solid line]. The diamonds indicate the mean depth and width values from latitudes $45.5^{\circ}-46^{\circ}$ measured in the five models (see triangles in Fig. 9). The error bars show the 25 th and 75 th percentiles. The root-mean-square percent error (RMSPE) and root-mean-square error (RMSE) between each theory and the mean ocean model values are shown. 
when transport of the inflowing current was overestimated for demonstration purposes.

\section{b. Plume inflow path}

Inflowing particles in the plume inflow path were identified by an initial salinity $0.1 \mathrm{~g} \mathrm{~kg}^{-1}$ less than shelf salinity. Some of the plume particles enter on the upstream side of the mouth overlapping the other inflow paths as they neared channel, but many entered on the downstream side of the mouth after traveling downstream with the coastal current (Fig. 5b). This second group will be the focus of the discussion here.

The plume inflow path arose because the river plume turned a corner when exiting the channel mouth. Flow curvature produces a SSH low in all five models (Fig. 2, see contours around the downstream corner of the estuary mouth). The dynamic balance produced is different near the corner and on the outside of the turning streamlines, but a center-directed pressure gradient force is necessary for both scales. Near the corner, the dominant balance is cyclostrophic, but at distances beyond the Rossby radius, the balance becomes geostrophic (Cherniawsky and LeBlond 1986). Flow separation occurs if the angle of the corner is sufficiently large, although what constitutes a sufficiently large angle depends on the flow's Froude number (Garvine 2001). When flow separates, the flow travels past the corner before turning and making contact with the coastal wall at some point downstream and bifurcating. Most of the water travels downstream to form the coastal current, but some travels back toward the source (Cherniawsky and LeBlond 1986; Avicola and Huq 2003), consistent with the particle paths seen here.

Dynamically, the transition from geostrophic to cyclostrophic as a corner is approached is found in the time-averaged momentum terms from the base case. Near the corner, the pressure gradient is balanced primarily by the material derivative (which includes the unsteady term and advection, right side of Fig. 11c). Geostrophy dominates in cross sections further from the corner (right side of Figs. 11a,b). However, this pattern is less obvious in the Lagrangian momentum budget. The momentum is dominated by geostrophy everywhere, with a slight cyclostrophic element that decreases as particles approach the mouth (Fig. 10b). The cyclostrophic signal might be muddled by the inclusion of particles in the plume group that enter the channel at the upstream side.

If the freshwater Froude number and corner angle were reduced, the plume path would be reduced as well. This can be seen in the wide mouth case, where plume backwash does not occur on the downstream side of the channel (Figs. 6 and 7d). The freshwater Froude number is halved for the wide mouth case because the freshwater Froude number is inversely proportional to the cross-sectional area of the estuary mouth (Geyer and Ralston 2011; Geyer and MacCready 2014; Poggioli and Horner-Devine 2015). The wide mouth model also has the smallest corner angle of the models at $78^{\circ}$, compared with $84^{\circ}$ in the base case and $87^{\circ}$ in the narrow mouth case. The $78^{\circ}$ angle is still larger than the "small angle" values of $35^{\circ}-55^{\circ}$ cited for steady outflow conditions in the literature (Garvine 2001; Nof and Pichevin 2001).
However, in combination with the reduced Froude number, the $78^{\circ}$ angle appears to be sufficient to reduce, if not eliminate, flow separation and plume recirculation.

Flow separation has been recognized as important for bulge formation (Garvine 2001; Avicola and Huq 2003) and even as a method of generating recirculation back toward the mouth (Avicola and Huq 2003), but has not been considered as a source of flow into an estuary. This path of plume recirculation is a way of recycling estuarine outflow back in as inflow. A sharp corner angle and a large freshwater Froude number are hypothesized to be necessary for this path, so deltas would be less likely to produce plume recirculation and jettied estuary mouths may produce stronger plume recirculation. Tidal asymmetry in flow around the mouth may contribute as well, wherein tidal transport is jetlike during ebb but radially symmetric during flood. This would produce a net transport toward the estuary around the outer corners of the mouth.

\section{c. Upstream inflow path}

Particles were sorted into the upstream group if their initial position was less than 44.8. In the gentle slope and wide mouth cases, they are an extension of the downstream group (Figs. 7c,d). In the base case, steep slope, and narrow mouth cases, upstream particles are advected by anticyclonic eddies traveling upstream from the bulge (tracks in Figs. 7a,b,e; eddies visible in Figs. 2a,b,e). In the base case, movement around these eddies was cyclostrophic far from the mouth and becomes geostrophic near the mouth (Fig. 10c). Anticyclonic eddies that flow upstream are generated because the freshest part of the bulge is not the center of rotation. Estuarine outflow turns anticyclonically to form the downstream coastal current, but it entrains shelf water as it does so, becoming denser on the downstream side of the bulge and exerting upstream baroclinic pressure. Over time the bulge shifts upstream and eventually sheds anticyclonic eddies (Yankovsky 2000). The episodic shedding of anticyclonic eddies is necessary to balance the momentum flux of the downstream coastal current (Pichevin and Nof 1997). These eddies have a long period and small mass flux. In the models where these eddies occurred, only one or two were generated in the 4-month model run (Figs. 2a,b,e) and upstream particles were the least populated group (Fig. 6). The lack of eddies visible in the gentle slope case is likely because the eddy formation period is extended beyond the model run time when the plume velocity was reduced by friction. Given the multimonth time scale, these anticyclonic eddies are likely to be less important than the other sources of estuarine inflow in realistic settings.

The wide mouth case did not produce a bulge and did not produce upstream eddies. The lack of bulge in a wide estuary has been observed in laboratory experiments and attributed to the cyclonic influence of lateral shear within the wide channel outcompeting inertial rotation. The result was recirculation of outgoing water back toward the freshwater source before it reached the mouth (Huq 2009). Because particles were only released on the shelf in these experiments, recirculation within the channel is not visible in the particle paths (Fig. 5d), but inchannel recirculation would explain the relatively fresh upstream 
edge of the wide channel (Fig. 2d). Ultimately a downstream current does form, but the turning radius is smaller because of the reduced freshwater Froude number (described in section $4 \mathrm{~b}$ ) and the associated anticyclone is small.

In summary, upstream inflow was driven toward the estuary when anticyclonic eddies were shed by the bulge. These are generated because outflow entrains shelf water as it circulates the bulge, continually shifting the center of mass away from the center of rotation (Yankovsky 2000). Further, these eddies occur episodically to balance the momentum flux of the coastal current (Pichevin and Nof 1997). They are a small source of mass flux to the estuary and occur on multimonth time scales and are therefore unlikely to be significant for most applications.

\section{d. Relative importance of inflow paths}

The downstream inflow path could be assumed to be the most important, but evidence in this study does not conclusively support that assumption. The downstream inflow path was the sole focus of earlier analytical work on inflow (Beardsley and Hart 1978; Masse 1990). However, when compared with the other groups, the downstream inflow group was not the most populated particle group (Fig. 6).

There are a number of reasons Fig. 6 could be misleading. The particles do not represent volume transport and were distributed more densely in shallow water, with the intention of resolving the boundary layers at all depths. Therefore, there would be more plume particles per volume transport of inflow than there would be downstream inflow particles, which originated in the deepest water. When there are similar counts of downstream and plume particles (e.g., the base case or steep slope in Fig. 6), the downstream path almost certainly accounted for a greater volume of transport. In the gentle slope and wide mouth cases, the two cases where upstream inflow did not originate from the bulge, upstream inflow is functionally an extension of downstream inflow, and could be justifiably categorized as such. The particle counts are most useful for comparisons of groups between the models, and less useful for comparisons between groups in a single model.

Ultimately, the relative importance of inflow paths depends on the application. The downstream inflow path was the source of the deepest shelf water and would thus be the most valuable for understanding the sources of nitrate or water with low $\mathrm{pH}$ to an estuary (Fig. 8). The path of recirculation from the plume into the estuary can effectively lengthen residence time. For other applications, all transport paths into an estuary may need to be considered.

\section{e. Limitations and future work}

The particle tracking used an ocean model time step that was sufficient to resolve the tidal forcing but may have been insufficient to capture the overtides, which are commonly generated in small bays and inlets (DiLorenzo et al. 2019). This has an unknown impact on particle behavior in the estuarine channel. Momentum budget analyses were only performed for the base case model because of constraints of time and computational resources, further momentum and transport analyses could strengthen the hypotheses made about the mechanisms driving plume and upstream shelf inflow.

This study focused on inflowing currents that arise on the shelf away from the mouth and bulge. The dynamics of inflow in those regions remain an open topic for future study. Inflow in this region is interesting and important, as the dynamics of the bulge and mouth have been shown to be sensitive to the presence of a return current at the channel mouth (Yankovsky 2000).

The next step toward understanding inflow is to perform experiments using a similar model under upwelling- and downwelling-favorable winds. Wind forcing has been observed to displace and bifurcate plumes (Hickey et al. 2005). The ATW solution has predicted that inflow originates upwind of the estuary (Beardsley and Hart 1978; Masse 1990), but a three-dimensional primitive equation model like ROMS may reveal new results, as it did for the no-wind case. Upwelling circulation includes Ekman transport in the boundary layers and a geostrophic current in the middle of the water column (Lentz and Fewings 2012). The geostrophic current could change the direction from which inflow is sourced (Masse 1990). The impact of shelf currents on inflow has been explored in some previous work. Model results and observations at the mouth of Chesapeake Bay suggest that in the presence of an ambient shelf current, estuaries will source inflow primarily from upstream relative to the shelf current, even when that is left of the channel mouth in the Northern Hemisphere (ValleLevinson et al. 1996, 1998; Masse 1990). Beyond that, it would be important to validate the source of inflow in the results from the idealized model with high-resolution realistic models of estuaries. Further validation with observations would also be beneficial. Additionally, the role of shelf stratification on inflow could be examined, as well as the role of topographic features such as undersea canyons.

\section{Conclusions}

The shelf source of inflow to an estuary has been examined here in five idealized, three-dimensional primitive equation models. The prior body of work on the inflow problem consisted of analytical two-layer ocean models styled on the arrested topographic wave (ATW) solution (Csanady 1978; Beardsley and Hart 1978; Masse 1990). This study sought to answer two questions: where is the ATW solution applicable, and where do previously neglected dynamics spin up secondary sources of inflow?

The ATW solution was applicable downstream of the estuary with the plume front forming an effective coastline. In the particle tracking experiments, particles in this region that followed these dynamics were referred to as the downstream group. Momentum budgets showed that dynamics were dominantly geostrophic with sufficient alongshore friction for the inflowing current to cross isobaths. At the plume front, the presence of an inflowing current adjacent to the downstream coastal current was posited to increase thermal wind shear. However, a theoretical exploration of this effect found that it would only deepen the front by $10 \%-20 \%$ relative to a plume front on a quiescent shelf. 
Two secondary sources of inflow arose from dynamics that were neglected in previous shelf inflow literature. The first was recirculation from the plume, which arises because of flow separation at the corner of the mouth. Plume recirculation may have implications for estuarine residence time and may especially be important for jettied estuaries. The second novel source of inflow from the shelf arose from anticyclonic eddies that were shed by the bulge and propagated upstream. These eddies were formed slowly and had little net mass transport, so this source is unlikely to be important for most applications.

Understanding where the inflow current lies on the shelf is important for understanding the transport pathways on the shelf and into the estuary. These pathways move salt, thermal content, nutrients, oxygen, and invasive species larvae. Therefore, understanding the source of inflow on the shelf has consequences for estuarine dynamics, shelf dynamics, biology, chemistry, and the future of ice.

Acknowledgments. The corresponding author would like to thank David Darr for his assistance with the computers and Jacob Steinberg for his counsel regarding figure design. The authors are grateful for the insights from dedicated anonymous reviewers which greatly strengthened the manuscript. This project was funded by the National Science Foundation under Grant OCE-1634148.

Data availability statement. The data that support the findings of this study are stored in NetCDF format on hard drives at the University of Washington. Model output and analysis code are available upon request from the corresponding author.

\section{REFERENCES}

Alford, M. H., and P. MacCready, 2014: Flow and mixing in Juan de Fuca Canyon, Washington. Geophys. Res. Lett., 41, 1608-1615, https://doi.org/10.1002/2013GL058967.

Avicola, G., and P. Huq, 2003: The characteristics of the recirculating bulge region in coastal buoyant outflows. J. Mar. Res., 61, 435463, https://doi.org/10.1357/002224003322384889.

Banas, N. S., B. M. Hickey, P. MacCready, and J. A. Newton, 2004: Dynamics of Willapa Bay: A highly unsteady, partially mixed estuary. J. Phys. Oceanogr., 34, 2413-2427, https://doi.org/ 10.1175/JPO2637.1.

— , P. MacCready, and B. M. Hickey, 2009: The Columbia River plume as cross-shelf exporter and along-coast barrier. Cont. Shelf Res., 29, 292-301, https://doi.org/10.1016/j.csr.2008.03.011.

Beardsley, R. C., and J. Hart, 1978: A simple theoretical model for the flow of an estuary onto a continental shelf. J. Geophys. Res., 83, 873-883, https://doi.org/10.1029/JC083iC02p00873.

Brasseale, E. A., E. W. Grason, P. S. McDonald, J. Adams, and P. MacCready, 2019: Larval transport modeling support for identifying population sources of European green crab in the Salish Sea. Estuaries Coasts, 42, 1586-1599, https://doi.org/ 10.1007/s12237-019-00586-2.

Burchard, H., and Coauthors, 2018: The Knudsen theorem and the Total Exchange Flow analysis framework applied to the Baltic Sea. Prog. Oceanogr., 165, 268-286, https://doi.org/10.1016/ j.pocean.2018.04.004.

Chapman, D. C., 1985: Numerical treatment of cross-shelf open boundaries in a barotropic coastal ocean model.J. Phys. Oceanogr.,
15, 1060-1075, https://doi.org/10.1175/1520-0485(1985)015<1060: NTOCSO $>2.0 . \mathrm{CO} ; 2$.

_ , and S. J. Lentz, 1994: Trapping of a coastal density front by the bottom boundary layer. J. Phys. Oceanogr., 24, 1464-1479, https://doi.org/10.1175/1520-0485(1994)024<1464:TOACDF> 2.0.CO;2.

Cherniawsky, J. Y., and P. H. LeBlond, 1986: Rotating flows along indented coasts. J. Fluid Mech., 169, 379-407, https://doi.org/ 10.1017/S0022112086000691.

Csanady, G. T., 1978: The arrested topographic wave. J. Phys. Oceanogr., 8, 47-62, https://doi.org/10.1175/1520-0485(1978) 008<0047:TATW $>2.0$.CO;2.

Davis, K. A., N. S. Banas, S. N. Giddings, S. A. Siedlecki, P. MacCready, E. J. Lessard, R. M. Kudela, and B. M. Hickey, 2014: Estuary-enhanced upwelling of marine nutrients fuels coastal productivity in the U.S. Pacific Northwest. J. Geophys. Res. Oceans, 119, 8778-8799, https://doi.org/ 10.1002/2014JC010248.

DiLorenzo, J. L., P. Huang, and T. O. Najarian, 2019: Overtide generation in small inlet-bay systems. J. Waterw. Port Coast. Ocean Eng., 145, 04019020, https://doi.org/10.1061/(ASCE) WW.1943-5460.0000524.

Feely, R. A., S. R. Alin, J. A. Newton, C. L. Sabine, M. Warner, A. Devol, C. Krembs, and C. Maloy, 2010: The combined effects of ocean acidification, mixing, and respiration on $\mathrm{pH}$ and carbonate saturation in an urbanized estuary. Estuarine Coastal Shelf Sci., 88, 442-449, https://doi.org/10.1016/j.ecss.2010.05.004.

Flather, R. A., 1976: A tidal model of the northwest European continental shelf. Mem. Soc. R. Sci. Liege, 6, 141-164.

Garvine, R. W., 1995: A dynamical system for classifying buoyant coastal discharges. Cont. Shelf Res., 15, 1585-1596, https:// doi.org/10.1016/0278-4343(94)00065-U.

- 2001: The impact of model configuration in studies of buoyant coastal discharge. J. Mar. Res., 59, 193-225, https://doi.org/ $10.1357 / 002224001762882637$.

Geyer, W. R., and D. K. Ralston, 2011: The dynamics of strongly stratified estuaries. Water and Fine Sediment Circulation, E. Wolanski and D. S. McLusky, Eds., Vol. 2, Treatise on Estuarine and Coastal Science, Academic Press, 37-51, https:// doi.org/10.1016/B978-0-12-374711-2.00206-0.

- , and P. MacCready, 2014: The estuarine circulation. Annu. Rev. Fluid Mech., 46, 175-197, https://doi.org/10.1146/annurevfluid-010313-141302.

Giddings, S. N., and Coauthors, 2014: Hindcasts of potential harmful algal bloom transport pathways on the Pacific Northwest coast. J. Geophys. Res. Oceans, 119, 2439-2461, https://doi.org/10.1002/ 2013JC009622.

Godin, G., 1972: The Analysis of Tides. University of Toronto Press, 264 pp.

Hench, J. L., and R. A. Luettich, 2003: Transient tidal circulation and momentum balances at a shallow inlet. J. Phys. Oceanogr., 33, 913-932, https://doi.org/10.1175/1520-0485(2003)33<913: TTCAMB $>2.0$. CO;2.

Hickey, B., S. Geier, N. Kachel, and A. MacFadyen, 2005: A bidirectional river plume: The Columbia in summer. Cont. Shelf Res., 25, 1631-1656, https://doi.org/10.1016/j.csr.2005.04.010.

Horner-Devine, A. R., R. D. Hetland, and D. G. MacDonald, 2015: Mixing and transport in coastal river plumes. Annu. Rev. Fluid Mech., 47, 569-594, https://doi.org/10.1146/annurevfluid-010313-141408.

Huq, P., 2009: The role of Kelvin number on bulge formation from estuarine buoyant outflows. Estuaries Coasts, 32, 709-719, https://doi.org/10.1007/s12237-009-9162-z. 
Jackson, R. H., and Coauthors, 2019: Meltwater intrusions reveal mechanisms for rapid submarine melt at a tidewater glacier. Geophys. Res. Lett., 47, e2019GL085335, https://doi.org/10.1029/ 2019GL085335.

Knudsen, M., 1900: Ein hydrographischer Lehrsatz. Hydrogr. Mar. Meteor., 28, 316-320.

Lentz, S. J., and K. R. Helfrich, 2002: Buoyant gravity currents along a sloping bottom in a rotating fluid. J. Fluid Mech., 464, 251-278, https://doi.org/10.1017/S0022112002008868.

— , and M. R. Fewings, 2012: The wind- and wave-driven innershelf circulation. Annu. Rev. Mar. Sci., 4, 317-343, https:// doi.org/10.1146/annurev-marine-120709-142745.

Lorenz, M., K. Klingbeil, P. MacCready, and H. Burchard, 2019: Numerical issues of the Total Exchange Flow (TEF) analysis framework for quantifying estuarine circulation. Ocean Sci., 15, 601-614, https://doi.org/10.5194/os-15-601-2019.

MacCready, P., 2011: Calculating estuarine exchange flow using isohaline coordinates. J. Phys. Oceanogr., 41, 1116-1124, https:// doi.org/10.1175/2011JPO4517.1.

_ and W. R. Geyer, 2010: Advances in estuarine physics. Annu. Rev. Mar. Sci., 2, 35-58, https://doi.org/10.1146/annurev-marine120308-081015.

$\longrightarrow,-$, and H. Burchard, 2018: Estuarine exchange flow is related to mixing through the salinity variance budget. $J$. Phys. Oceanogr., 48, 1375-1384, https://doi.org/10.1175/JPO-D-170266.1.

Margules, M., 1906: Zur Sturmtheorie. Meteor. Z., 23, 481-497.

Masse, A. K., 1990: Withdrawal of shelf water into an estuary: A barotropic model. J. Geophys. Res., 95, 16 085-16 096, https:// doi.org/10.1029/JC095iC09p16085.

McCabe, R. M., P. MacCready, and B. M. Hickey, 2009: Ebb-tide dynamics and spreading of a large river plume. J. Phys. Oceanogr., 39, 2839-2856, https://doi.org/10.1175/2009JPO4061.1.

Nof, D., and T. Pichevin, 2001: The ballooning of outflows. J. Phys. Oceanogr., 31, 3045-3058, https://doi.org/10.1175/1520-0485(2001) 031<3045:TBOO>2.0.CO;2

North, E. W., R. R. Hood, S.-Y. Chao, and L. P. Sanford, 2006: Using a random displacement model to simulate turbulent particle motion in a baroclinic frontal zone: A new implementation scheme and model performance tests. J. Mar. Syst., 60, 365-380, https://doi.org/10.1016/j.jmarsys.2005.08.003.

Pawlowicz, R., O. Riche, and M. Halverson, 2006: The circulation and residence time of the strait of Georgia using a simple mixing-box approach. Atmos.-Ocean, 45, 173-193, https:// doi.org/10.3137/ao.450401.

Pichevin, T., and D. Nof, 1997: The momentum imbalance paradox. Tellus, 49A, 293-319, https://doi.org/10.3402/ tellusa.v49i2.14484.

Poggioli, A. R., and A. R. Horner-Devine, 2015: The sensitivity of salt-wedge estuaries to channel geometry. J. Phys. Oceanogr., 45, 3169-3183, https://doi.org/10.1175/JPO-D14-0218.1.

Ralston, D. K., W. K. Geyer, and J. A. Lerczak, 2008: Subtidal salinity and velocity in the Hudson River estuary: Observations and modeling. J. Phys. Oceanogr., 28, 753-770, https://doi.org/ 10.1175/2007JPO3808.1.

Shchepetkin, A. F., and J. C. McWilliams, 2005: The Regional Ocean Modeling System (ROMS): A split-explicit, free-surface, topography-following-coordinate oceanic model. Ocean Modell., 9, 347-404, https://doi.org/10.1016/j.ocemod.2004.08.002.

Sutherland, D. A., and F. Straneo, 2012: Estimating ocean heat transports and submarine melt rates in Sermilik Fjord, Greenland, using acoustic Doppler current profiler (ADCP) velocity profiles. Ann. Glaciol., 53, 50-58, https://doi.org/ 10.3189/2012AoG60A050.

Umlauf, L., and H. Burchard, 2003: A generic length-scale equation for geophysical turbulence models. J. Mar. Res., 61, 235265, https://doi.org/10.1357/002224003322005087.

Valle-Levinson, A., J. M. Klink, and G. H. Wheless, 1996: Inflows/outflows at the transition between a coastal plain estuary and the coastal ocean. Cont. Shelf Res., 16, 1819-1847, https://doi.org/ 10.1016/0278-4343(96)00016-7.

- C. Li, T. C. Royer, and L. P. Atkinson, 1998: Flow patterns at the Chesapeake Bay entrance. Cont. Shelf Res., 18, 1157-1177, https://doi.org/10.1016/S0278-4343(98)00036-3.

Visser, A. W., 1997: Using random walk models to simulate the vertical distribution of particles in a turbulent water column. Mar. Ecol. Prog. Ser., 158, 275-281, https://doi.org/10.3354/ meps158275.

Yankovsky, A. E., 2000: The cyclonic turning and propagation of coastal buoyant discharge along the shelf. J. Mar. Res., 58, 585-607, https://doi.org/10.1357/002224000321511034.

and D. C. Chapman, 1997: A simple theory for the fate of buoyant coastal discharges. J. Phys. Oceanogr., 27, 1386-1401, https://doi.org/10.1175/1520-0485(1997)027<1386:ASTFTF> 2.0.CO;2 